\title{
A Space Design Teaching Model Using Virtual Simulation Technology
}

\author{
https://doi.org/10.3991/ijet.v13i06.8585 \\ Jialing $\mathrm{Wu}$ \\ University of Science and Technology Liaoning, Anshan, Liaoning \\ jadie19@163.com
}

\begin{abstract}
With the rapid advancement of information technology, virtual reality technology has also gradually developed, accompanied by the dramatic growth of virtual reality experiment technology. At present, the space designoriented virtual experiment teaching method usually contributes to the formation of undesired experiment habits among students, such as caring less about experiment instruments, attaching less importance to the norms of experiment operation, and the lack of awareness of safety precautions. At the same time, virtual experiment may lead to reduced communications in the learning process and fewer opportunities for students to exercise interpersonal skills, thus affecting the teaching effect to a certain extent. On this basis, a teaching method of applying virtual simulation technology to the course of space design was proposed in this study. The analysis of the current development status and characteristics of virtual simulation technology was followed by a detailed description of the use of software in the construction entity and a series of computer-aided teaching and developing processes concerning space, design, function, etc. in the case of space design. Through the survey, it was found that students have more recognition of the new teaching method and their learning efficiency is improved, indicating that this teaching model is significantly better than other traditional teaching methods.
\end{abstract}

Keywords-Virtual reality technology, Experiment teaching model, Space design

\section{Introduction}

The progress of information technology has brought the development of the entire Internet world. As a result of its high-speed evolution, the Internet is able to provide increasingly diversified services and functions. The most important reason for the existence of the Internet lies in the interaction of information between different personal computers and individuals. The Internet can eliminate the barrier of information between individuals and realize the communication of all resources from the software level to the hardware level. In practice, the most typical mode of information exchange and communication is the exchange of curriculum knowledge that occurs in school. In the classroom, the teacher is the sender of information and students are the 
receivers of information. Meanwhile, the teacher can also obtain the corresponding teaching achievement information based on the feedback of students' corresponding learning situation [1]. Therefore, the Internet also reflects in the virtual world based on this mode of exchange of information.

If classroom teaching in school is applied to the Internet, a new teaching model of online courses will be formed to overcome the restrictions of geography, time and other material conditions [2]. Apart from the field of education, information, electronics and other fields in the society are also exploring hardware and software suitable for online course teaching, so that online course teaching develops as the main way that adapts to teaching in the new era.

Therefore, "space design", an architecture course, was employed in this study as the main online course teaching content, to study the feasibility of online course teaching. Besides, online course teaching proposed in this study was effectively combined with simulation virtual technology to generate an online course teaching model with virtual reality functions, which can effectively improve the teaching efficiency and teaching level of architecture courses and cultivate architecture talents with more design experience for the community.

\section{State of the art}

With the development of computers and sensors, simulation virtual technology has gradually become a hot topic in the field of science and technology. At the same time, noticing the outstanding advantages of simulation virtual technology in their application to teaching practice, many schools, companies and research institutes at home and abroad have begun to pay attention to the development and application of simulation virtual technology in course teaching. At present, a large number of virtual reality laboratories and virtual reality teaching systems have been used in many colleges and universities.

The United States was the first country to invest in virtual reality laboratories and teaching systems. As early as the end of the 20th century, University of Virginia in the United States put forward the concept of virtual reality laboratory. With the development of virtual reality technology and the gradually deepened research on virtual reality technology in the United States, lots of virtual reality experiment systems have come into being in the United States. Massachusetts Institute of Technology (MIT), the best-known university in the United States, has developed a virtual experiment teaching system called Microelectronics Web Lab [3] that cannot only be used for teaching related microelectronics courses in MIT, but also allow external students to gain access to corresponding resources, thus improving the teaching effect of the course in terms of information sharing and teaching experiment research. At University of Central Florida, a virtual system laboratory named Visual System Laboratory was also established [4]. The advantage of this experiment system over that of the virtual experiment system in MIT lies in its ability to more effectively combine 3D graphical representation by computer with virtual reality technology and a higher level of the entire virtual reality human-computer interaction. Carnegie Mellon Uni- 
versity in the United States also integrated virtual simulation technology with the course of chemistry, developing the corresponding virtual chemical laboratory. In this virtual chemical laboratory, students can wear the corresponding head-mounted display and joystick to capture oxygen and hydrogen atoms in the vividly simulated virtual scenes to create water molecules [5].

The study of virtual experiment teaching system in China did not start until the 21st century, so that China still lags behind developed countries such as the United States and Britain in the scale and degree of realization of virtual reality laboratories, many colleges, universities and institutes in China have made corresponding positive research on virtual laboratory. Through communicating with MIT, Dalian University of Technology established the first virtual reality laboratory in China [6], which incorporated Microelectronics Web Lab of MIT into the course experiment of microelectronics and has acquired a good response. At the same time, Dalian University of Technology conducted an in-depth study of the virtual experiment system of MIT and used Virtools technology which can effectively achieve the functions of virtual reality. Dalian University of Technology also applied Virtools technology in the construction of virtual chemical laboratories. Using the virtual experiment teaching technology, students can select the appropriate virtual experiment equipment for the corresponding virtual chemistry experiment. The application of virtual experiment in education can effectively improve the teaching quality and is of great importance to reforms of the experiment teaching model. However, it is not a panacea, but has many shortcomings and deficiencies. First, the experiment environment and experiment objects of virtual experiments are all virtual items. Although the high simulation level enables learners to be immersed in the virtual environment and have difficulties in distinguishing between true and false, these objects are not real items after all. During the experiment operation, it is hard for the experimenter to get the real feeling and experience via various senses [7]. Second, virtual experiments are applications developed by using virtual reality technology and computer technology. In this sense, the experiment process, experiment phenomena, experiment feedback have already been designed in advance. Nevertheless, the actual experiment process is a very complicated process. Any subtle change in the order of experiment operations, experiment conditions, experiment time and many other factors will have a large impact on the experiment results, and therefore it is difficult for a virtual experiment to simulate the uncertain phenomena that may occur in a real experiment [8]. Third, virtual experiment usually contributes to the formation of undesired experiment habits among students, such as caring less about experiment instruments or devices, waste of experiment drugs, attaching less importance to the norms of experiment operation, and the lack of awareness of safety precautions, which are not conducive to the development of scientific and rigorous experiment attitudes [9]. Fourth, virtual experiment may lead to reduced communications in the learning process, increasing problems and fewer opportunities for students to exercise interpersonal skills, thus affecting the teaching effect to a certain extent [10].

To overcome the shortcomings above, a virtual experiment teaching model based on Virtools was put forward in this study. This experiment teaching model mainly relies on the course of "space design", which is mainly used in the teaching of archi- 
tecture courses. Generally, this course requires students and teachers to provide this design course practical feasibility. The innovation of the model lies in: First, this model uses the simulation resource teaching and training system which can engage architecture students in virtual simulation training consisting of three modes, namely teaching, training and examination, covering training in various aspects like the structure and principle of the system and equipment, operation, maintenance, troubleshooting and repair. Second, the design of the system follows the theoretical principle of the lesson plan teaching method, which is conducive to strengthening the interaction between teachers and students and the communication between students. In short, the virtual experiment teaching model based on Virtools proposed in this study is the application of the corresponding simulation virtual technology in the architecture direction. Meanwhile, a case teaching method that is suitable for the teaching of architectural courses was also introduced, for the purpose of providing reference for corresponding multimedia course teaching.

\section{Specific Ways of Integrating Simulation Virtual Technology into Space Design Teaching}

\subsection{Integrating the case teaching method into space design teaching}

The case teaching method [11] can effectively allow students to experience the environment and to incorporate their current knowledge into the entire typical case, playing a good role in substitution. The main characteristic of this teaching method is the establishment of teaching situations suitable for the whole course teaching according to the corresponding teaching content in the course and the learner's own learning mode and method. The case teaching method can make full use of the multimedia technology and computer information resources now available to create a vivid and creative classroom teaching scenario that enables students to take full advantage of their own knowledge and deepen their understanding of knowledge in realistic teaching situations, thus building a more complete knowledge structure system. This teaching method can express complex theories in simple terms through practical engineering examples or real-life examples, so as to effectively improve students' ability to analyze problems and stimulate their enthusiasm, which is also the most significant advantage brought by the case teaching method.

\subsection{Integrating the simulation resource packet technology based on Virtools into space design teaching}

The simulation resource packet technology is a kind of data packet technology which can effectively support the virtual experiment teaching model proposed in this study by using the related software of Virtools technology [12]. This technology can determine the simulation resource packet suitable for the whole teaching process according to the specific content and training way of different professions. Besides, the simulation resource packet technology can effectively realize the modular man- 
agement of information resources and effectively improve the operation efficiency of the entire virtual experiment teaching model. The entire simulation resource packet technology mainly includes four simulation resource packet modules: structure principle simulation resource packet, post operation simulation resource packet, maintenance simulation resource packet and troubleshooting simulation resource packet. The relationship between the simulation resource packet technology and the entire experiment teaching model is shown in Figure 1.

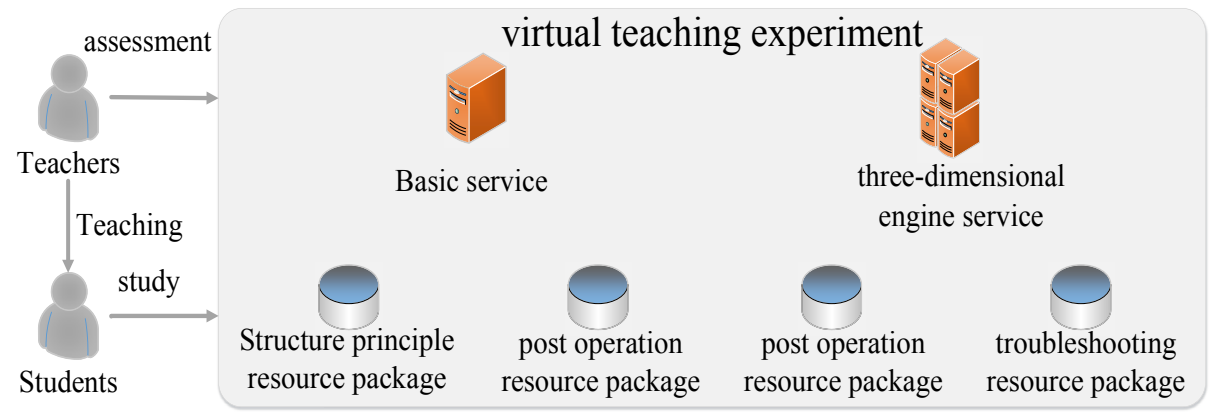

Fig. 1. Relationship between simulation resource packets and experiment teaching

The structure principle simulation resource packet is the most important experiment frame of the entire virtual experiment teaching. Its major function is to enable the clear three-dimensional virtual presentation of the entire virtual experiment teaching. The pixel coordinates of the presentation can be simulated by the structural principle through formula (1) and formula (2). The content that needs to be displayed in virtual reality can be effectively displayed in real time through the virtual reality device. It can achieve the unified function connection between devices, and train the cognitive ability and operation ability of students or virtual experiment teaching operators concerning the entire device structural components, working principle, working structure and the relationship between devices.

$$
\begin{aligned}
& x^{\prime}=x \cos \theta-y \sin \theta \\
& y^{\prime}=y \cos \theta+x \sin \theta
\end{aligned}
$$

The post operation simulation resource packet is the simulation resource packet technology developed based on the corresponding structural standards and resources environment provided by the entire structure principle simulation resource packet to meet the use requirements of the entire virtual experiment teaching model. The maintenance simulation resource packet offers the underlying maintenance feature for the entire virtual experiment operation system. For the virtual experiment teaching model, the troubleshooting simulation resource packet is a functional resource packet put forward by combining the functions of the maintenance simulation resource packet to play a complementary role. 
The simulation resource packet technology relies on the use of Virtools virtual experiment simulation technology. The main compilation language of Virtools virtual experiment simulation technology is the VSL programming language. This language can effectively integrate the simulation resource packet technology proposed in this study into the entire virtual experiment teaching. At the same time, as Virtools virtual experiment simulation technology does not cover the corresponding threedimensional modeling technology, the combination of the simulation resource packet technology and Virtools virtual experiment simulation technology can form unique virtual experiment teaching of online courses. Virtools virtual experiment teaching is characterized by the use of the VSL programming language which is not single combinations of character codes, but corresponding combinations through the existing Building Blocks. When Building Blocks are given the appropriate objects and attributes, and the combination of corresponding functions and placement of the order of different Building Blocks are finished in the entire script editing area, the cycle of different modules can form a complete virtual experiment teaching model, which contains both the corresponding module functions provided by Virtools and the existing three-dimensional modeling capabilities contained in the simulation resource packet. The two functions weree combined to form the unique Virtools-based simulation resource packet technology in this study.

\subsection{Integrating simulation virtual technology into the space design teaching model}

The virtual experiment teaching model is mainly used in the teaching of "space design", an architecture course. The main research object of such courses is the interior space after decoration. Through the placement of movable decorations such as furniture, interior decoration and ornaments, the overall interior space in the building reflects the decoration taste or the interior design style. Therefore, what the entire "space design" teaching needs most is to the capacity to determine the appropriate virtual experiment operation environment and realize the placement of specific mobile decorations in the simulated three-dimensional virtual building space through the three-dimensional virtual experiment operation. Meanwhile, it is also necessary for the whole course teaching to include the corresponding information learning module, the feedback module for exchanges between students and the experiment evaluation module. The overall framework of the virtual experiment teaching model is shown in Figure 2. 


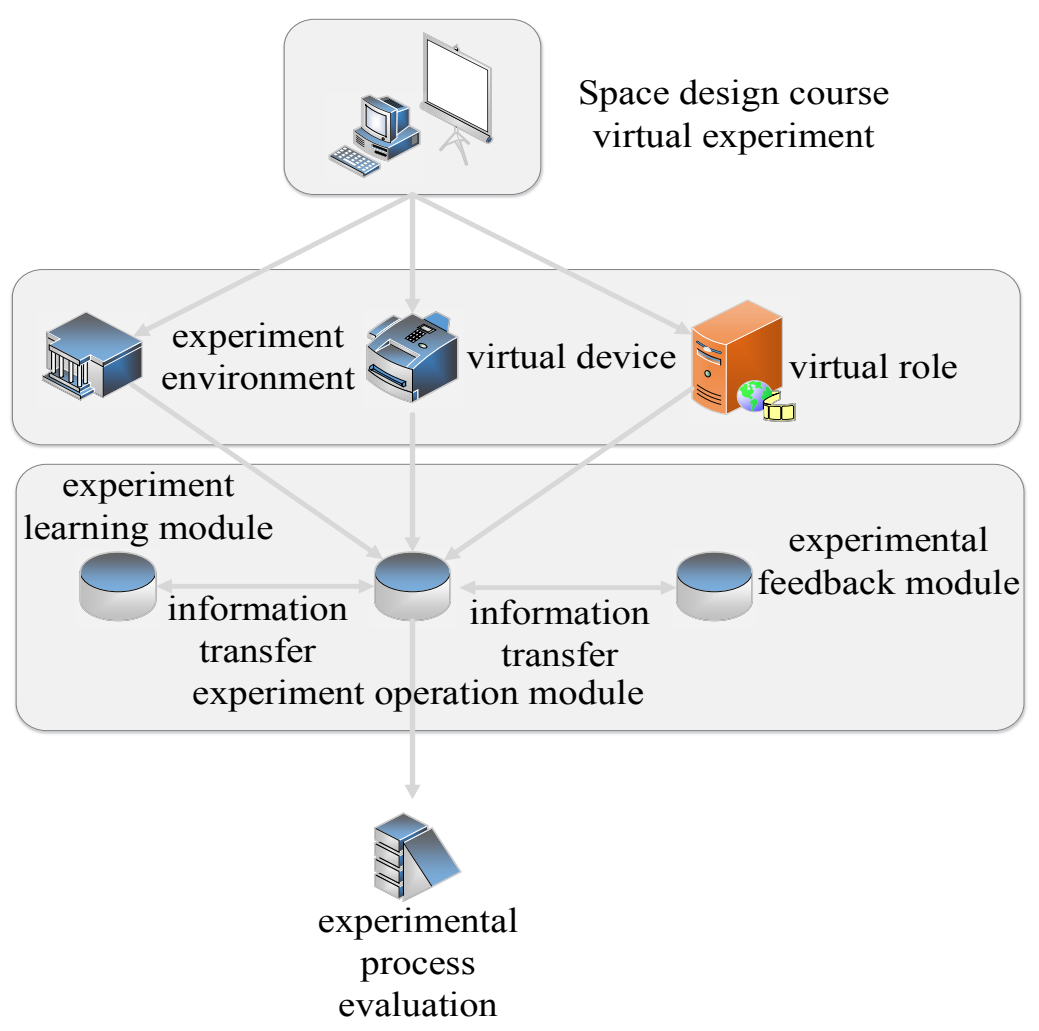

Fig. 2. Space design teaching model integrating simulation virtual technology

\section{$4 \quad$ Teaching Case and Teaching Effect}

\subsection{Teaching case}

Experiment operation. The Building Blocks module in Virtools is mainly used in the design of the entire experiment operation module. The major form of the graphical operation codes for this module is shown in Figure 3. The virtual experiment operation module is primarily aimed at enabling students to control their positions and postures of placing different decorations in a three-dimensional virtual space through input devices such as somatosensory and wireless mouse according to the corresponding virtual reality images they receive in the $3 \mathrm{D}$ glasses or the computer screen, and allowing experimenters to switch between different perspectives in the virtual space for the purpose of adjusting to a suitable angle to obtain the same visual experience as the actual decoration. 


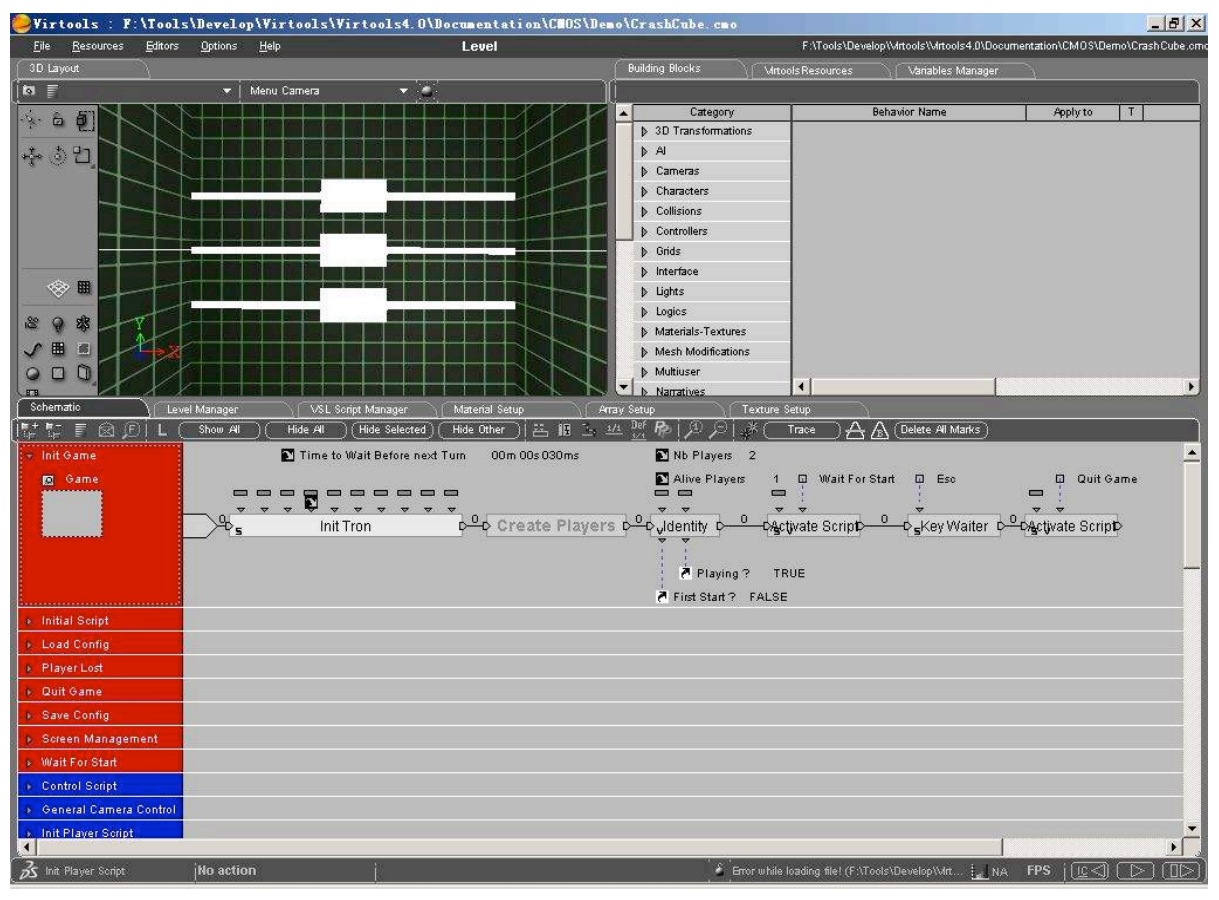

Fig. 3. Screenshot of application of the Virtools-based virtual experiment teaching model

Experiment Learning. In the process of carrying out the virtual technology experiment, the corresponding learning module should be designed for users to acquire knowledge, including the corresponding precautions in the whole operation process, the experiment demonstration process, etc., so that students can obtain the appropriate classroom knowledge on the output interface of the device in the two-dimensional form. The demonstration process is shown in Figure 4. The whole experiment learning module contains three parts, namely equipment function demonstration, experiment demonstration and experiment instruction. In this experiment learning module, the appropriate video text file should be used to display these resources.

Experiment feedback. In the entire virtual experiment teaching process, the feedback of the effect is also the focus of the whole teaching model. With the feedback, the users and teachers of experiment teaching can know in real time whether the user utilizes the method correctly. At the same time, the experiment feedback module can well prevent the user from damaging the experiment equipment due to incorrect operation of virtual experiment teaching. A partial screenshot of the Virtools-based virtual experiment teaching feedback module is shown in Figure 5. Figure 6 illustrates the video screenshot of the experiment operation of placing boxes and decorative balls. 


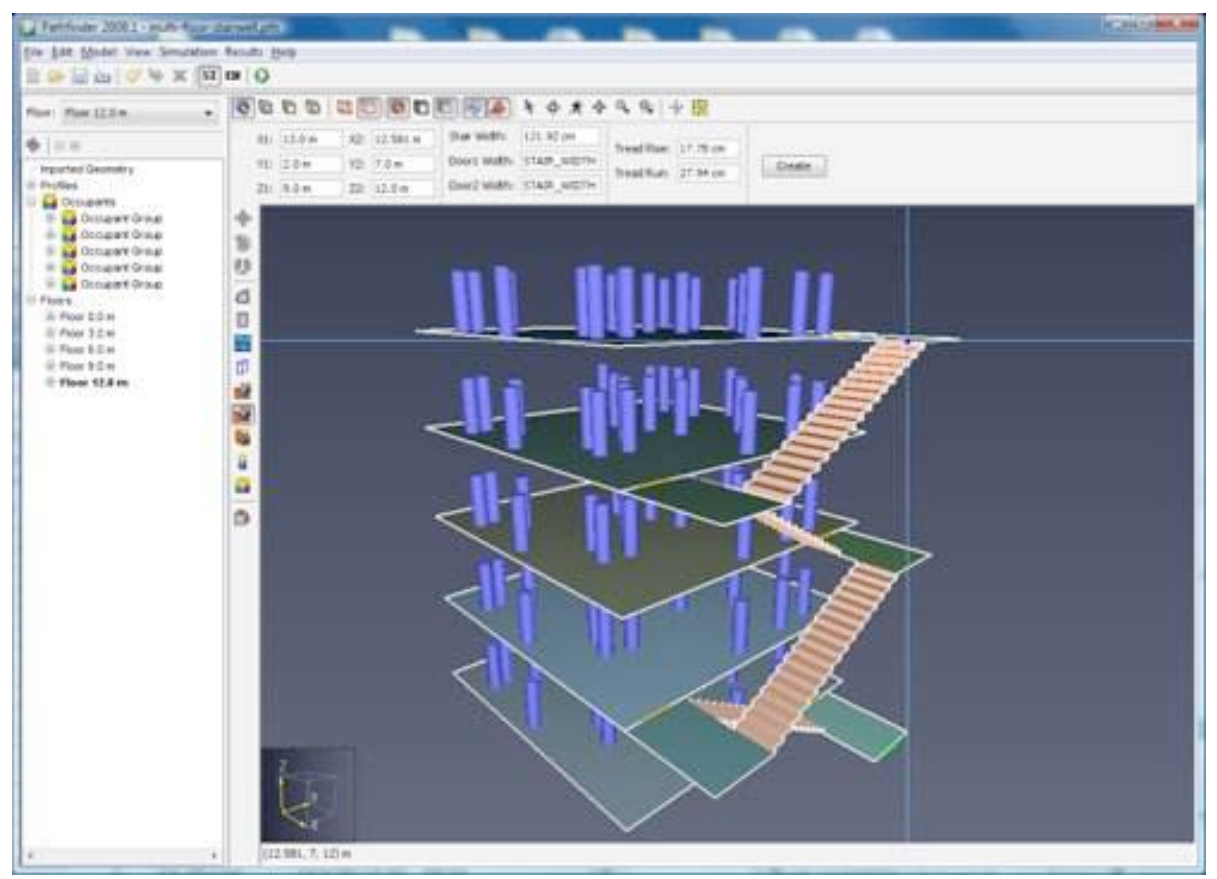

Fig. 4. Demonstration of using the left mouse button to convert the perspective

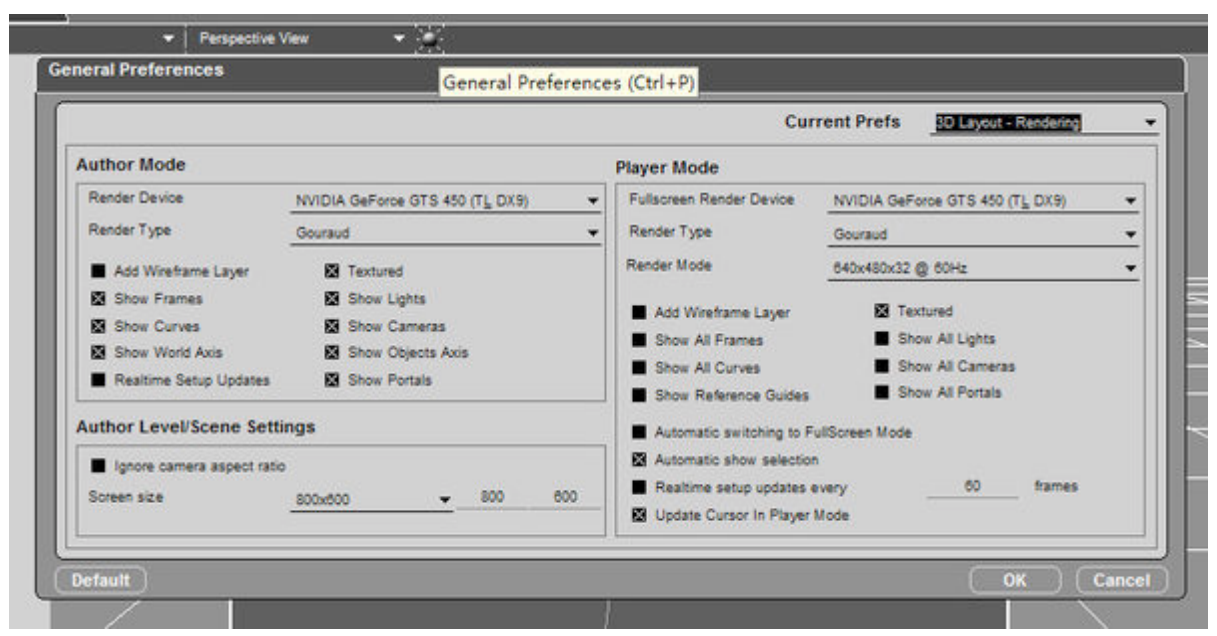

Fig. 5. Partial screenshot of the Virtools-based virtual experiment teaching feedback module 


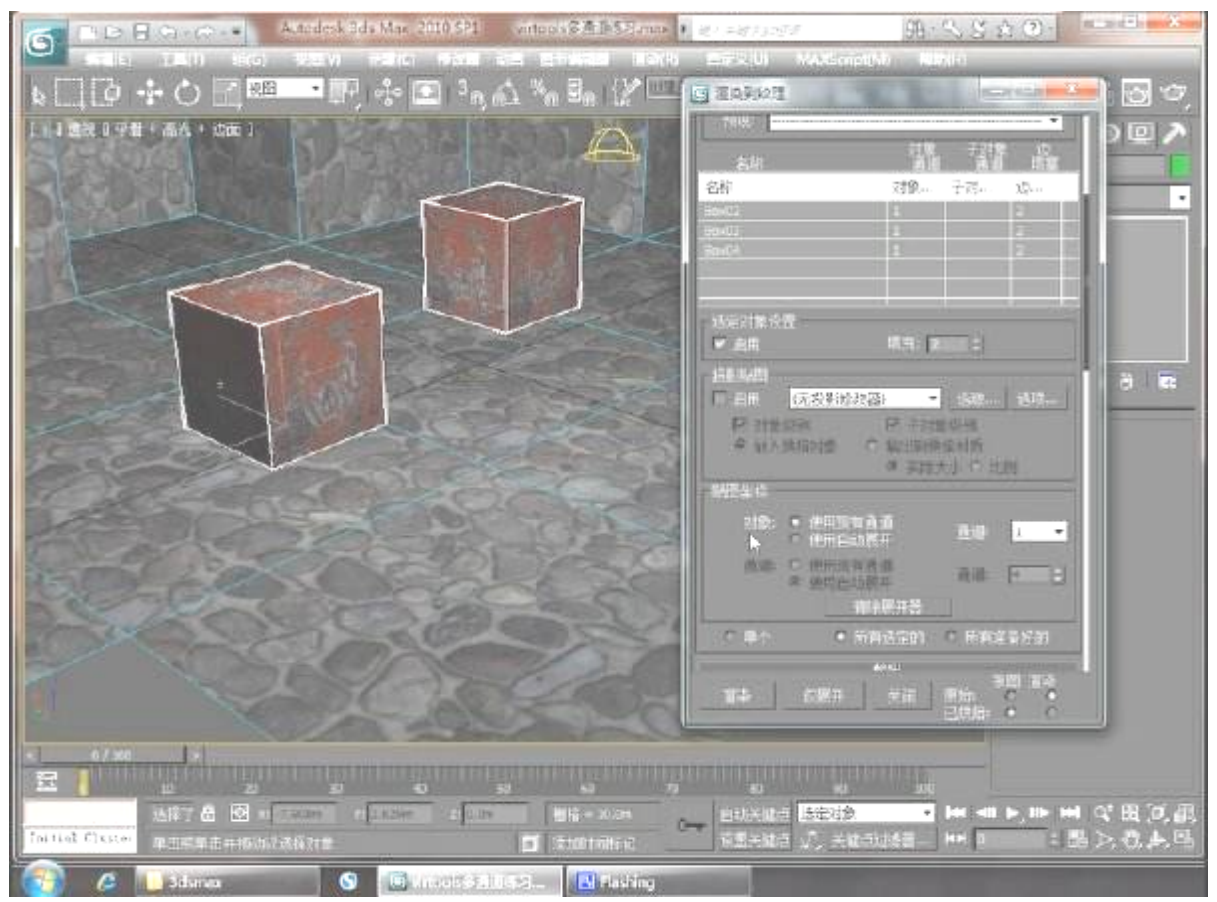

Fig. 6. Video screenshot of the experiment operation of placing boxes and decorative balls

\subsection{Teaching effect}

Based on Virtools software, a virtual experiment teaching model was designed in this study for the architecture course of "space design". This virtual experiment teaching model can realize the free placement of corresponding decorations in a certain architectural space. The effect of the entire experiment process is shown in Figure 7. In order to test the teaching effect of the whole virtual teaching system, two classes of "space design" were selected in this study as the experiment group and the control group respectively. A questionnaire was designed to explore the satisfaction with "space design" among students in the group that used the virtual teaching system and the group which did not used the virtual teaching system. The researchers also investigated the corresponding teaching effect evaluation among students in the experiment group which used the virtual teaching system. There are 23 students in both classes, suggesting a total of 46 participants.

Table 2 shows the teaching effect evaluation among students in the experiment group which used the virtual teaching system.

As can be seen from Table 1 and Figure 7 regarding the comparison of the experiment group and the control group, the virtual teaching system proposed in this study is more in line with students' learning acceptance characteristics. The satisfaction degree of the experiment group with "space design" is far higher than that of the control group, fully showing that using the virtual teaching system proposed in this study 
has some advantages in improving satisfaction with the teaching of architectural courses. It can be observed from Table 2 concerning the investigation on the experiment group's evaluation of the teaching effect after using the virtual reality teaching system proposed in this study, using the virtual reality teaching system effectively improves the efficiency of learning "space design" and other architectural courses, and enables students to combine the corresponding knowledge learned in the classroom with the formal space design process. Therefore, it not only arouses students' interest, but also contributes to the more harmonious relationship between teachers and students in the process of experiment practice. Students also made it clear in the investigation that they hope to continue using the virtual reality experiment teaching system in the subsequent course of "space design".

Table 1. Comparison between traditional teaching platform with 3D multimedia teaching platform

\begin{tabular}{|l|c|c|c|c|}
\hline \multicolumn{1}{|c|}{ Group } & Very satisfaction & Satisfactory & Normal & Not Satisfaction \\
\hline Experimental group & 63 & 23 & 11 & 0 \\
\hline Control group & 36 & 37 & 27 & 0 \\
\hline
\end{tabular}

Table 2. Teaching effect evaluation

\begin{tabular}{|l|c|c|c|c|}
\hline \multicolumn{1}{|c|}{ Investigation content } & Very agree & Agree & Normal & Disagree \\
\hline Strengthen the mastery of knowledge & 46.09 & 29.13 & 24.78 & 0 \\
\hline $\begin{array}{l}\text { Makes the relationship between teachers and students har- } \\
\text { monious }\end{array}$ & 60.43 & 28.48 & 11.09 & 0 \\
\hline $\begin{array}{l}\text { Stimulates interest in learning } \\
\text { It is necessary to continue to use }\end{array}$ & 45.13 & 47.17 & 3.7 & 0 \\
\hline Investigation content & 50.43 & 37.83 & 11.74 & 0 \\
\hline
\end{tabular}

\section{Conclusions}

The simulation resource packet technology was combined with the teaching of space design experiment course in this study. The initial analysis of the current development status of simulation virtual technology was followed by the combination of the corresponding characteristics of simulation virtual technology for the application of a virtual teaching training system based on simulation resource packet by using Virtools and then followed by the description of the use of simulation technology for physical construction and space, design, function and other computer-aided teaching and development processes. A questionnaire was employed to examine students' and enterprises' evaluation of the teaching effect, leading to the following conclusions:

1. Throughout the operation of the virtual reality experiment, the boring process of knowledge learning can be directly displayed through plenty of multimedia means, so as to improve students' learning motivation and improve their academic performance. 
2. Case teaching put forward in this study exposes students to real case scenarios and improves the communication between teachers and students in some virtual teaching. Case teaching attaches great importance to the subjectivity and enthusiasm of students. It enhances the interaction between teachers and students during the analysis and discussion of teaching cases, assists students to apply the acquired knowledge to solve case problems and thereby enable students to obtain autonomous learning methods and opportunities.

3. The virtual experiment teaching model can cultivate students' sense of responsibility. Responsibility education for students is also an important aspect of quality education in schools. Notably, the major of architecture aims to solve the contradiction between structural safety and economy. Reasonable application of engineering accident cases can prompt students to consider not only objective factors, but also subjective factors appropriately.

In short, with the development of virtual reality technology, the virtual experiment teaching model proposed in this study can have a broader space for development. Therefore, this virtual reality experiment teaching model can provide a significant and feasible direction for the corresponding teaching reform.

\section{References}

[1] Lowes, S. Online Teaching and Classroom Change: The Trans-Classroom Teacher in the Age of the Internet. Innovate Journal of Online Education, 2008, vol. 4(3), pp. 1-5.

[2] Glahn, R., \& Gen, R. Progenies in education: The evolution of Internet teaching. Community College Journal of Research \&Practice, 2002, vol. 26(10), pp. 777-785. https://doi.org/10.1080/10668920290104868

[3] Chen, X., Zhang, C., Liu, D., et al. Teaching Reform of Chemical Reaction Engineering Based on Virtual Simulation Technology. Guangzhou Chemical Industry, 2015, vol. 21, pp. 183-184.

[4] Tripathy, B.K., Maiti, A. Remote Laboratories: Design of Experiments and Their Web Implementation. Journal of Educational Technology \& Society, 2013, vol. 16(3), pp. 220233.

[5] Tetko, I.V., Gasteiger, J., Todeschini, R., et al. Virtual Computational Chemistry Laboratory - Design and Description. Journal of Computer-Aided Molecular Design, 2005, vol. 19(6), pp. 453-463. https://doi.org/10.1007/s10822-005-8694-y

[6] Du, B.G., Tan, Y.B., Feng, L.Y., et al. Application of virtual reality technology in the internal combustion engine disassembly practice teaching. Laboratory Science, 2015, vol. 18(5), pp. 168-170.

[7] Yadav, A., Shaver, G.M., Meckl, P. Lessons Learned: Implementing the Case Teaching Method in a Mechanical Engineering Course. Journal of Engineering Education, 2010, vol. 99(1), pp. 55-69. https://doi.org/10.1002/j.2168-9830.2010.tb01042.x

[8] Yunyue, L., Fang, Y. Research and application of paper mill simulation systems based on virtual DPU technology. Agro Food Industry Hi Tech, 2017, vol. 28(1), pp. 429-432.

[9] Xiong, W., Wang, Q.H., Huang, Z.D., et al. A framework for interactive assembly task simulationin virtual environment. International Journal of Advanced Manufacturing Technology, 2016, vol. 85(5-8), pp. 955-969. https://doi.org/10.1007/s00170-015-7976-3 
[10] Marfisischottman, I., Labat, J.M., Carron, T. Building on the Case Teaching Method to Generate Learning Games Relevant to Numerous Educational Fields. 2013, vol. 8174(3), pp. 156-160.

[11] Li, Z. Application of Virtual Reality Technology Based on 3DSMAX and VIRTOOLS in Landscape Design. Journal of Anhui Agricultural Sciences, 2008, vol. 36(8), pp. 31983199 .

\section{Author}

Jialing Wu is a Lecturer in the University of Science and Technology Liaoning, Anshan 114051, China. (jadie19@163.com).

Article submitted 17 March 2018. Final acceptance 23 April 2018. Final version published as submitted by the author. 